\title{
Erratum
}

\section{Regional differences in cell density and cell genesis in the olfactory epithelium of the salamander, Ambystoma tigrinum}

Mackay-Sim, A. and Patel, U.

Experimental Brain Research (1984) 57: 99-106

One page 104 , paragraph 3 , line 11 , the sentence

"This observation is consistent with a similar anterior-to-posterior gradient in the numbers of receptor cells reported recently for another urodele amphibian, Triturus cristatus (Dubois-Dauphin et al. 1980) should read:

"This observation is contrary to another urodele amphibian, Triturus cristatus in which the posterior epithelium contained more receptor cells than the anterior (Dubois-Dauphin et al. 1980).

\section{Announcement}

\section{The Xth Internatioal Congress of Neuropathology will take place in Stockholm, Sweden, September 7-12, 1986}

For further information contact X International Congress of Neuropathology, c/o Stockholm Convention Bureau, P.O. Box 1617, S-111 86 Stockholm, Sweden.

There will be four major symposia: "energy crisis in the brain. Causes and consequences' (chairman: F. Plum, United States), 'viral infections' (chairman: R.T. Johnson, United States), 'pathobiology of the axon' (chairman: S. Waxman, United States) and 'neuro-transmitter and receptor systems in health and disease' (chairman: A. Dahlström, Sweden). In addition there will be daily plenary lectures on important developments in neuropathology and neurobiology, slide seminars on muscle diseases, intracranial tumours and tropical infections of the nervous system. Finally, free communications and workshops as well as poster sessions will be arranged.

Prof. P. Sourander will serve as president of the congress and Prof. A. Torvik is the chairman of the program committee. 